\title{
Analysis on Environmental Protection in Urban Planning and Con- struction
}

\author{
People 's Government of Qingguang Town, Beichen District, Tianjin 300401
}

\section{Analysis of the Function of Urban Environmental Protec- tion Planning}

The rapid development of society, urban environmental protection work is more and more attention, to further strengthen the urban environmental planning is very important.

1.1 Urban environmental protection planning to further promote sustainable development. On the current situation, in the development of urban construction more and more attention to balance the economy and environmental protection, environmental protection planning is to meet the needs of social development, while the effective balance of economic development, and therefore more and more attention.

1.2 The purpose of urban environmental protection planning is to use the smallest investment to obtain the greatest benefits. In the urban development environment is a very important part, to further strengthen the urban environmental protection planning will be able to achieve maximum economic benefits, and therefore need to pay attention.

\subsection{Urban environmental protec-} tion planning to further control pollution. Urban environmental protection planning will sound and improve the relevant rules and regulations, which can largely control the city pollution, but also to further enhance the public awareness of environmental protection, increase people's understanding of environmental protection.

\section{Environmental problems in urban planning}

2.1 Environmental awareness in urban planning is not strong

Urban planning for environmental issues has received high attention, but the actual application of the situation, some cities for these areas there are still many deficiencies, mainly because the city's relevant leaders do not attach great importance to this aspect, only concerned about the economy. The development of the environment has not attached great importance to ignore the environmental costs of economic development so that the effective implementation of sustainable problems there are many problems.

On the current situation, more and more projects in the construction of the city in the construction, but for the urban planning aspects of environmental issues did not pay much attention, especially in some small cities more obvious, only focus on economic development, for the environment wise, there are many deficiencies in protection. Not only that, because the strengthening of environmental protection is the need to invest a lot of cost, so the process of urban construction will be affected by the financial and human aspects of the direct impact on urban construction, resulting in a large environmental pollution.

\subsection{Excessive degree of air pollu-} tion

In the process of urban construction, the environmental problems need to pay much at
Abstract: With the rapid development of society, urban construction has been paid more and more attention. In the very important part of the urban construction is environmental protection, good environmental protection can effectively protect people's lives, and can better promote urban development, so the need to further strengthen its research. However, the current situation, there are still many problems in environmental protection, so in the practical application requires relevant personnel to take effective measures to control, and continue to strengthen environmental protection efforts, which can better promote the development of urban construction, to meet Sustainable development requirements. Based on this, this paper analyzes the environmental protection in urban planning and construction.

Key words: Urban planning and construction; environmental protection; measures

Published online: 15th July, 2017

tention. At present, due to the increasing construction projects, the environmental problems, especially air pollution, which directly affects the environment and people's health, thus need to pay attention. The main reason for the air pollution is due to 
the increasing number of heavy industrial plants in the city, such as cement plants, thermal power plants, etc., these plants will discharge a large number of harmful gases. In addition, the rapid development of society, private cars continue to increase in the process of driving a lot of car exhaust emissions, resulting in atmospheric pollution. In addition, if the gas station leaked, it will evaporate to form hydrocarbons, for this material is harmful to people's body. For the above mentioned substances into the air will be a direct pollution of the environment.

2.3 A large number of municipal waste pollution

In the development of the city must be mentioned is the garbage problem, the rapid development of society, the rapid development of the city has brought us a lot of convenience, but it also further increased urban pollution, such as the garbage generated beyond the original of the scope, making the environment is greatly affected, causing pollution. Because the garbage problem will make the city a great impact, in fact, can be learned that the pollution caused by garbage is very large, but also affect the overall beauty of the city, so the need to further strengthen its research, take effective measures to control.

\section{Environmental Protection Measures in Urban Planning}

\subsection{To improve environmental} awareness

For urban planning and construction needs from a number of aspects, in particular, should pay attention to environmental protection, so we need to further improve the awareness of environmental governance. In the process of urban planning need to strengthen this understanding, strengthen the environmental protection of knowledge construction, the overall urban planning should also closely linked to environmental protection, which can achieve urban environmental construction and environmental protection lock balance state, further increased the city Planning and construction of environmental protection efforts. Not only that, in the process of urban planning need to attach great importance to waste disposal and water environment management, from a number of aspects of urban planning and environmental management coordination, the use of scientific methods for urban planning and construction, to ensure that the process of urban planning and construction can be reasonable Of the garbage disposal and the use of resources, and also need to constantly improve the water environment management, so as to achieve the purpose of environmental protection.

3.2 Urban air pollution comprehensive renovation planning

Air pollution is a very important control content in urban environmental protection. In order to achieve reasonable control of air pollution, it is necessary to carry out the following aspects: 1) Strengthen the urban planning, for some large, high-polluting factories in the city Urban areas, at the same time to a reasonable control of the factory location, to prevent the occurrence of concentration, so as to ensure that the same area will not be excessive pollution phenomenon. 2) In the process of urban planning and construction, it is necessary to put some chemical plants with raw material supply relationship together, and the whole process needs to make full use of the generated exhaust gas. For example, the waste gas discharged from the factory can be produced by other factories Raw materials for its production, which can reasonably control the emissions of exhaust gas, but also to protect the role of the environment. 3 ) Planting green plants, forest cover can further alleviate the problem of environmental pollution, further reduce the wind speed, so that the large dust containing the landfall. Not only that, green plants also have a lot of efficacy, can absorb dust, so that the air contains suspended particles and other substances have been further controlled, effective control of air pollution.

3.3 Countermeasures for waste pol- lution

In the urban planning and construction of garbage problems need to attract our attention, so in practical application to pay attention to this aspect, for example, in life, we have to minimize the number of people thrown and, as far as possible not to use disposable tableware and other daily necessities. Garbage to be classified, to facilitate the re-use. At present, the incineration of waste cannot be recycled to take electricity, and construction and mainly for urban backfill or management projects, it should be noted that if it is toxic and harmful garbage on the need for its degradation, and deep in the non-aquifer. There are many ways to deal with the garbage, in the practical application of the situation according to the city, while the introduction of new technologies, new technology, new materials, new methods of "four new technologies" to better promote the development of the city.

In short, in order to meet the rapid development of urban demand, but also to allow more people into the city, urban planning is imperative. In the process of urban construction planning is very important part of the environmental protection, so to further strengthen its research is necessary.

\section{References:}

[1] Xu Yichun. Analysis of Urban Construction in the Ecological Environment Planning [J]. Modern Economic Information, 2008,07: 111.

[2] Huang Zhijun. Urban Planning and Construction of Environmental Protection Strategy Analysis [J]. Private Technology, 2014,03: 279.

[3] Yao Yuanwen. Study on Environmental Protection Related Problems in Urban Planning [J]. Charm China, 2010,07: 345. 